"C 2020 IEEE. Personal use of this material is permitted. Permission from IEEE must be obtained for all other uses, in any current or future media, including reprinting/republishing this material for advertising or promotional purposes, creating new collective works, for resale or redistribution to servers or lists, or reuse of any copyrighted component of this work in other works." 


\title{
A Disturbance Rejection Based Control Strategy for Five-Level T-Type Hybrid Power Converters with Ripple Voltage Estimation Capability
}

\author{
Shakil Ahamed Khan, Student Member, IEEE, Youguang Guo, Senior Member, IEEE, Yam P. Siwakoti, \\ Senior Member, IEEE, Dylan Dah-Chuan Lu, Senior Member, IEEE, and Jianguo Zhu, Senior Member, \\ IEEE
}

\begin{abstract}
This paper proposes a robust control strategy for five-level T-type (5L-T) hybrid power converters to achieve superior dynamic performance for regulating effectively the DC-bus voltage under external disturbances and generating high-quality grid current at the same time. A new filter-less DC-bus ripple voltage estimation method and a simple technique to remove this ripple component from the measured DC-bus voltage of a single-phase converter are developed. A sliding-mode control (SMC) incorporated with an extended-state observer (ESO) is employed for the outer voltage control loop, and to calculate dynamically the input (i.e. the active power reference) for the inner current tracking controller. The proposed SMC-ESO approach presents a high disturbance rejection capability and robustness against the DC-bus load variation, and thus, significantly improves the dynamic and steady-state performance during system uncertainties. Moreover, a finite control setmodel predictive control algorithm is derived as the inner current controller to track their references while balancing the DC-bus capacitor voltages. The effectiveness of the proposed controller is demonstrated and verified through measurement results.
\end{abstract}

Index Terms-Disturbance rejection, FCS-MPC, power quality, ripple voltage, single-phase, voltage control.

\section{INTRODUCTION}

$\mathbf{S}$ SINGLE-PHASE voltage-source converters (VSCs) are the main component to integrate DC-bus microgrids comprised of electric vehicles (EVs), energy storages (ESs), and renewable energy sources (RESs) into the distribution grid. As the active front end (AFE) rectifiers, they $\mathrm{c}$ an $\mathrm{c}$ ontrol the power factor through power flow control to p rovide ancillary services when required [1]-[3]. It is thus of great importance to design a robust control system for these converters. In such a single-phase power conditioning system, the DC-bus voltage has a significant impact on the control of current and power flow between the microgrid and the distribution grid. The DC-bus voltage control is a challenging task due to the presence of the double-grid frequency $\left(2 \omega_{0}\right)$ pulsating power component that flows through the DC side of the converter and causes double-line frequency voltage ripple in the DC-bus voltage. The presence of this voltage ripple in the DC-bus is inherent in both inverters and rectifiers [4]. This ripple voltage in a feedback control system degrades the quality of $\mathrm{AC}$ current by adding additional harmonics, and therefore, must be removed in order to achieve high-quality power conversion. A low bandwidth filter is usually used to remove this low frequency ripple component completely. The low bandwidth filter, however, introduces a significant phase delay in the DCbus voltage control loop. As a result, the control performance to regulate the DC-bus voltage is affected during transients. To regulate effectively the DC-bus voltage, a high bandwidth is desired, and thus, a trade-off should be made between the conflicting constraints, such as the grid current quality and dynamic performances [5].

Various methods have been proposed to address difficulties associated with the DC-bus ripple voltage [6]-[14]. The coupled inductor and loop compensator based approaches are presented in [6]-[8]. However, these approaches require a high order filter with poles and zeros at low frequencies. Several active filter based techniques have been introduced in [4], [9]-[13]. These techniques require additional energy storage devices and converters in the DC side, which increases the cost and control complexity, and decreases the overall efficiency. To remove this ripple, a notch filter (NF) and a finite impulse response (FIR) filter tuned at $2 \omega_{o}$ were reported in [5] [15], and [14], respectively. However, a low bandwidth must be selected during the filter design for complete elimination of this ripple, which results in slower dynamic response during transients. To settle the conflicting constraints of the grid current distortion and dynamic performance, a new method is required that can improve the $\mathrm{AC}$ current quality while realizing fast dynamic performance during transients.

This paper introduces a new filter-less approach to remove the double grid-frequency voltage ripple component from the measured bus voltage. By analyzing the DC-bus voltage, an expression of the DC-bus ripple voltage component is obtained. 
Instead of using an additional filter $\mathrm{o} \mathrm{h}$ ardware, $\mathrm{t}$ he new method uses the existing phase-locked-loops (PLLs) information to calculate the DC-bus ripple voltage. The DC component can then be deduced by subtracting the estimated ripple from the measured DC-bus voltage. Since the proposed approach can eliminate the need for filter or a dditional $h$ ardware, the difficult trade-off between the conflicting constraints (i.e. grid current harmonics and transient performance) can be avoided, enabling the simple design of the voltage control loop. The proposed approach can improve the transient performance without distorting the $\mathrm{AC}$ current.

Another essential control aim is to self-support the DC-bus voltage under disturbances such as sudden variation of the active power drawn by the converters due to the load changes. The bus voltage regulation is usually done by the outer voltage controller, where a feedback loop is used to update the control input (the active power reference). Numerous control techniques have been reported in the literature to achieve this control objective. The most commonly employed methods are the proportion-integration (PI) based controllers due to their simple structures. These controllers employ PI with constant gain parameters for both the outer voltage controller and inner current controller [16]. Several PI-based methods have been reported in [7], [17]-[22]. The performance of these methods depends on the PI controller gain parameters that need to be updated under different operating conditions. However, most of these methods did not consider these variations. Thus, the dynamic performance will be affected by using constant PI gain parameters under different operating conditions. A PI-based method is presented in [7], which considers both conflicting $\mathrm{c}$ onstraints, $\mathrm{s}$ uch a $\mathrm{s}$ t he $\mathrm{A} \mathrm{C} g$ rid c urrent quality and the DC-bus voltage fluctuations. $\mathrm{H}$ owever, $\mathrm{t}$ his method increases the grid current distortion at low bus capacitor value.

To reduce the DC-bus voltage fluctuations d uring external disturbances, the feedforward control approaches are reported in [18], [23], [24]. These methods feed forward the external power to reduce the voltage fluctuation. H owever, these methods require additional sensors to measure the external power, which increases the cost and decreases the reliability. Nevertheless, these approaches increase the grid current harmonics due to the coupling between the DC and AC sides. The major drawback of the PI-based strategy is the dependence of dynamic and steady-state performances on the tuning of PI gain parameters in both the outer voltage controller and the inner current tracking controller. Therefore, the overall system behavior will be affected by using the constant PI gain parameters during external disturbances.

The other commonly studied approaches are the direct power control (DPC) [25], DPC based on Fuzzy method [26], and model predictive DPC [27], [28]. Among these methods, the predictive control method provides the best performance, but the parameter sensitivity is the major problem of the predictive controller [16], [27]. Recently, several advanced methods have been proposed in three-phase applications to improve the control performance such as the multiple-vector model predictive power control [29], predictive current control [30], model predictive DPC [31], and model predictive DPC with finite control set [32]. These control methods are usually governed by the conventional PI-based outer voltage control loop. Therefore, the control performance of these methods still suffer from poor dynamic behaviour or overshoot during system parameter uncertainties. Moreover, these control approaches are not studied in single-phase applications, where the control performances are affected by the DC-bus voltage ripple elimination methods. Therefore, it is much desired to design an advanced control method to improve the dynamic and steady state performance against the disturbances, and system parameter fluctuations.

In order to overcome the limitations of the existing methods, this paper proposes a sliding mode control (SMC) incorporated with an extended state observer (ESO) as the outer voltage controller. The SMC-ESO significantly improves the dynamic and steady state performance in the presence of disturbances. The available literature shows that single-phase applications traditionally employ the three-level H-bridge converter. In contrast, this paper adopts the five-level T-type converter in order to improve the AC grid current quality, and reduce the required voltage rating of the semiconductor devices and EMI filter size. However, realizing the multilevel voltage at the AC side will be affected by the use of series connected capacitor in the converter structure if further control action is not taken into account. In this work, a finite control set model predictive control (FCS-MPC) algorithm is derived to track the desired current references. A cost function is formulated to balance the voltages across the capacitors connected in series in the DC-bus of the converter.

\section{System Model And Problem Statement}

\section{A. Analysis of the $D C$-bus voltage}

The presence of double grid frequency $\mathrm{AC}$ voltage ripple component on the top of the DC-bus voltage is inherent in a single-phase grid-connected AC-DC power converter. Since a feedback loop is used to regulate the DC-bus voltage, this ripple component modulates the generated output $\mathrm{AC}$ current of the converter if the voltage ripple is not filtered properly. Consequently, the converter current is distorted by this ripple component. This ripple voltage should be managed properly in order to avoid the adverse effect on the control performances such as slow dynamic performance during transients and increased harmonic content in the generated grid current. The value of the DC-bus voltage and its double grid frequency ripple component can be calculated by balancing the input and output power of the converter as presented below.

The grid voltage $v_{g}(t)$ and current $i_{g}(t)$ are assumed as

$$
\begin{gathered}
v_{g}(t)=V_{m} \sin (w t) \\
i_{g}(t)=I_{m} \sin (w t+\phi)
\end{gathered}
$$

where $V_{m}$ and $I_{m}$ are the peak values of the input voltage and current of the converter, respectively, $\omega$ is the angular frequency and $\phi$ the phase angle difference between the grid voltage and current.

To simplify the analysis, the single-phase AC-DC converter can be represented by an equivalent circuit, as shown in Fig. 1, and the power losses in the circuit are neglected. Thus, the 


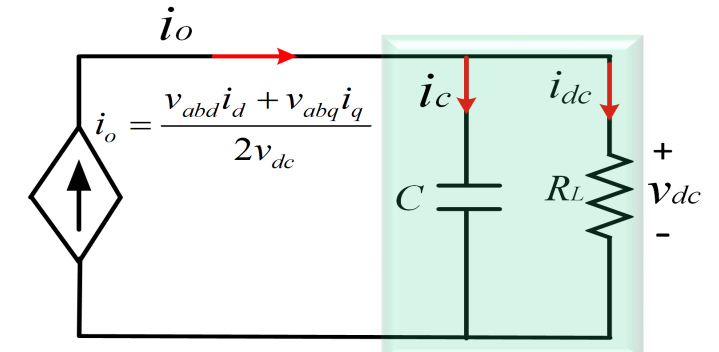

Fig. 1. Equivalent circuit of a single-phase AC-DC converter.

instantaneous input power at the grid-side can be calculated as

$$
P(t)=v_{g}(t) i_{g}(t)=\frac{V_{m} I_{m}}{2} \cos \phi-\frac{V_{m} I_{m}}{2} \cos (2 \omega t+\phi)
$$

The ripple voltage $\Delta v$ is small compared to the $\mathrm{DC}$ bus voltage when a large capacitor is used in the DC-bus. Therefore, the input power $P(t)$ operates at approximately constant voltage. The output current can be calculated as

$$
i_{0}(t) \cong \frac{P(t)}{V_{d c}}=\frac{V_{m} I_{m}}{2 V_{d c}} \cos \phi-\frac{V_{m} I_{m}}{2 V_{d c}} \cos (2 \omega t+\phi)
$$

The AC part of $i_{o}(t)$ flows through the DC-bus capacitor and the DC component flows through the load resistor $R_{L}$. The current through the bus capacitor can be expressed as

$$
C \frac{d v_{d c}(t)}{d t}=i_{0}(t)-\frac{v_{d c}(t)}{R_{L}}
$$

Multiplying both sides of (5) by $v_{o}(t)$, we have

$$
C v_{d c}(t) \frac{v_{d c}(t)}{d t}=P(t)-\frac{v_{d c}^{2}(t)}{R_{L}}
$$

From (6), it can be concluded that the power flowing into the bus capacitor $\mathrm{C}$ is the difference between the input power and the power consumed by the load resistor, $R_{L}$. The energy stored in the bus capacitor can be given as

$$
E(t)=\frac{1}{2} C v_{d c}^{2}(t)
$$

Thus, the power flowing through the bus capacitor can be written as

$$
\frac{d E(t)}{d t}=C v_{d c}(t) \frac{v_{d c}(t)}{d t}
$$

Substituting (7) and (8) into (6), we have

$$
\frac{d E(t)}{d t}=P(t)-\frac{2 E(t)}{R_{L} C}
$$

Solving (9), we obtain

$$
E(t)=E(0) e^{-\frac{2 t}{R_{L} C}}+e^{-\frac{2 t}{R_{L} C}} \int_{0}^{t} e^{\frac{2 \tau}{R_{L} C}} P(\tau) d \tau
$$

Considering that the grid voltage and current are in phase and substituting (10) into (7), one obtains the expression of the DC-bus voltage as given in (11). Fig. 2 shows a typical bus voltage waveform during turn-on obtained from (11).

As shown, the bus voltage waveform consists of double grid frequency ripple, steady-state DC and transient components. In a closed loop control system, the measured DC-bus voltage should be filtered to estimate the DC component of the

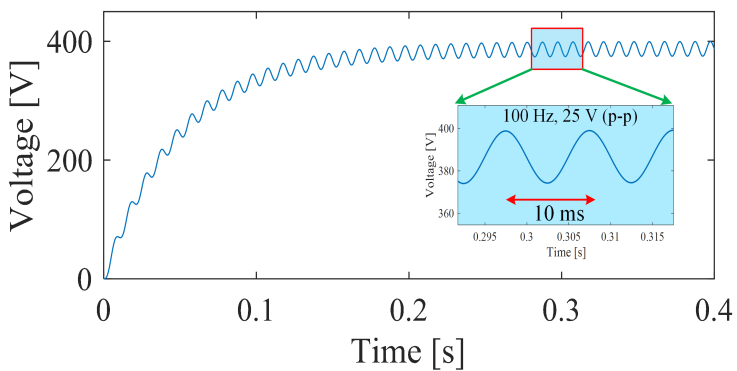

Fig. 2. DC-bus voltage waveform of a single-phase converter during turn-on transient, as given by (11).

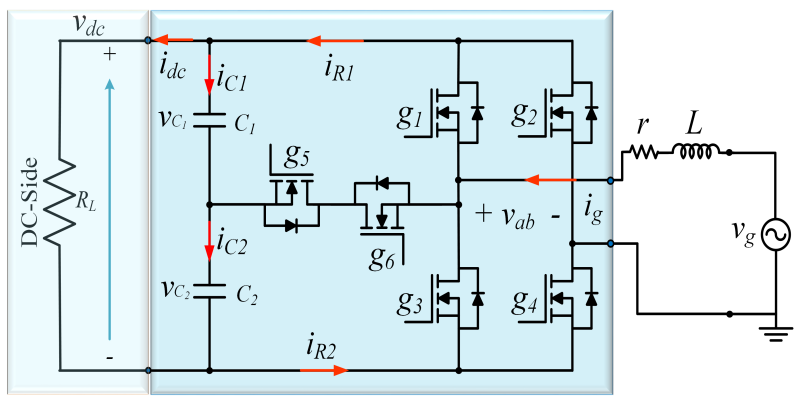

Fig. 3. Topology of the adopted single-phase T-type hybrid power converter.

bus voltage in order to avoid the harmonic distortion in the generated AC grid current by this ripple voltage. Moreover, the filtering method should provide a fast dynamic performance in calculating the DC component during the transients with zero steady-state error.

\section{B. Dynamic System Model}

Fig. 3 shows the power circuit of the single-phase fivelevel hybrid power converter under consideration, where the converter is connected to the power grid through a smoothing inductor of inductance, $L$, in series with winding resistance, $r$. Two capacitors, $C_{1}$ and $C_{2}$, connected in series and a resistive load $R_{L}$, are connected to the DC-bus. A step change of the load resistance, $R_{L}$, would cause a sudden variation of active power drawn by the converter from the power grid. In this paper, the step variation of the load resistance $R_{L}$ is considered as the unknown external disturbance to the converter.

According to the Kirchhoff's voltage and current laws, the dynamics of the grid current $i_{g}(t)$ and the DC-bus series connected capacitor voltages, $\left(v_{c_{1}}(t)\right.$ and $\left.v_{c_{2}}(t)\right)$, are governed by the following equations

$$
\begin{gathered}
L \frac{d i_{g}(t)}{d t}=v_{g}(t)-v_{a b}(t)-i_{g}(t) r \\
C_{1} \frac{d v_{C_{1}}(t)}{d t}=i_{R_{1}}(t)-i_{d c}(t)=i_{R_{1}}(t)-\frac{v_{d c}(t)}{R_{L}} \\
C_{2} \frac{d v_{C_{2}}(t)}{d t}=i_{R_{2}}(t)-i_{d c}(t)=i_{R_{2}}(t)-\frac{v_{d c}(t)}{R_{L}}
\end{gathered}
$$

where $v_{a b}$ is the converter output voltage, $i_{R_{1}}$ and $i_{R_{2}}$ are the internal current of the converter, and $i_{d c}$ is the DC-bus current. 


$$
v_{d c}(t)=\sqrt{\frac{2\left(E(0) e^{-\frac{2 t}{R_{L} C}}+e^{-\frac{2 t}{R_{L} C}}\left(\frac{C V_{m} R_{L} I_{m}\left(e^{\frac{2 t}{R_{L} C}}\right)}{4}-\frac{I_{m} V_{m}\left(\frac{C R_{L}\left(e^{\frac{2 t}{R_{L} C} \cos (2 \omega t)-1}\right)}{2}\right)+\frac{C^{2} R_{L}^{2} \omega e^{\frac{2 t}{R_{L} C}}}{2} \sin ^{2}(2 \omega t)}{2\left(C^{2} R_{L}^{2} \omega^{2}+1\right)}\right)\right)}{C}}
$$

Resolving the grid voltage, $\left(v_{g}\right)$, the converter voltage, $\left(v_{a b}\right)$, the inductor current, $\left(i_{L}\right)$, and the DC-bus voltage, $\left(v_{d c}\right)$ into their $d$ and $q$ components at the power grid frequency $\left(\omega_{o}\right)$, we can express the system dynamics model as follows:

$$
\begin{gathered}
\frac{d i_{d}}{d t}=\frac{v_{d}}{L}-\frac{v_{a b d}}{L}-\frac{r}{L} i_{d}+i_{q} \omega_{o} \\
\frac{d i_{q}}{d t}=\frac{v_{q}}{L}-\frac{v_{a b q}}{L}-\frac{r}{L} i_{q}-i_{d} \omega_{o} \\
\frac{C}{2} \frac{d v_{d c}}{d t}=\frac{v_{a b d} i_{d}+v_{a b q} i_{q}}{2 v_{d c}}-\frac{v_{d c}}{R_{L}}
\end{gathered}
$$

where $i_{d}, v_{d}$ and $v_{a b d}$ are the $d$-axis, and $i_{q}, v_{q}$ and $v_{a b q}$ are the $q$-axis parts in $d q$ rotating frame of $i_{g}, v_{g}$, and $v_{a b}$, respectively.

This nonlinear system consists of three state variables $i_{d}, i_{q}$ and $v_{d c}$ and two control inputs $v_{a b d}$ and $v_{a b q}$. For simplification, the winding resistance $r$ is neglected in this analysis. When the system is at the equilibrium point, (15)(17) can be simplified as

$$
\begin{gathered}
v_{a b d}=v_{d}+i_{q} \omega_{o} L \\
v_{a b q}=-i_{d} \omega_{o} L \\
\frac{v_{d c}^{2}}{R_{L}}=\frac{v_{d} i_{d}}{2}
\end{gathered}
$$

From (18)-(20), it can be concluded that the DC-bus voltage depends on the $d$-axis component, $i_{d}$, of the grid current. The $q$-axis component of the grid current, $i_{q}$, controls the power factor. For unity power factor operation, the $q$-axis component must be set to zero (i.e. $i_{q}=0$ ).

\section{Necessity of Modelling Uncertainties}

To simplify the controller design, during system modelling, various assumptions are often made to ignore the non-ideal factors, including the inductor winding resistance, switching losses, DC-bus capacitance variation, and external disturbances due to the load variations, resulting in inaccurate prediction of the actual system behavior under different operating conditions, and affecting effectiveness of the DC-bus voltage controller. Therefore, in order to design a robust controller, these system uncertainties must be considered properly.

\section{Proposed Control Scheme}

The proposed control approach aims to improve the steadystate and transient performances in regulating the DC-bus voltage under unexpected external disturbances, and achieving the highest grid current quality. The controller design is based on the cascaded structure. Fig. 4 illustrates the controller block

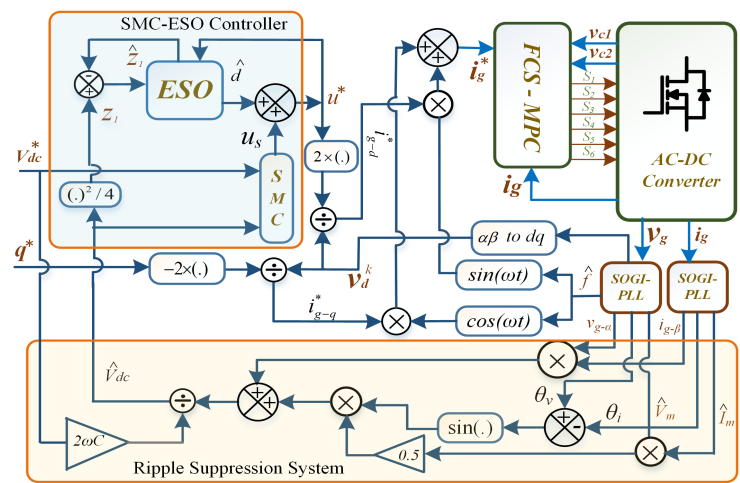

Fig. 4. Proposed control system of the hybrid power converter.

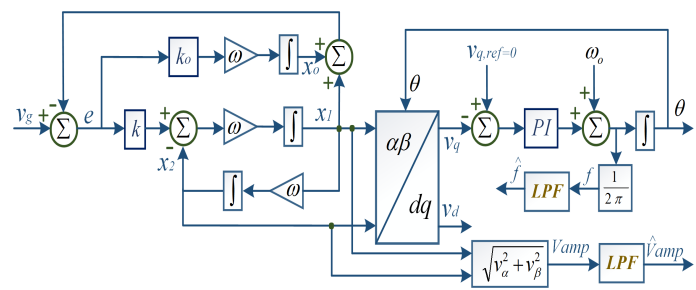

Fig. 5. Block diagram of the PLL.

diagram, including an outer voltage controller and an inner current controller. The outer voltage regulation loop consists of a sliding mode controller (SMC), an extended state observer (ESO), and a DC-bus voltage ripple estimator. The ESO is designed to estimate the disturbances to the converter, and an SMC is employed in parallel with the ESO to calculate the reference active power value for the internal current tracking controller. In this paper, a filter-less method is used to estimate the DC value of the bus voltage, which provides a fast transient performance in approximating the DC-value. Besides that, the inner current tracking controller is designed based on a finite control set-model predictive control (FCS-MPC) algorithm.

\section{A. Proposed ripple voltage estimation method}

In the proposed method, the DC-bus ripple voltage is calculated based on the estimated quantities obtained from the PLLs. The block diagram of the PLL is illustrated in Fig. 5. The estimated ripple is then subtracted from the measured bus voltage to acquire the DC component of the bus voltage. From (4), the current through the DC-bus capacitor can be expressed as

$$
C \frac{d v_{d c}(t)}{d t}=-\frac{V_{m} I_{m}}{2 V_{d c}} \cos (2 \omega t+\phi)
$$

where $v_{d c}=V_{d c}+\Delta v$. 
By integrating (21), the magnitude of the ripple voltage component can be approximately as

$$
\Delta v \cong-\frac{V_{m} I_{m}}{4 V_{d c} \omega C}
$$

Therefore, the bus voltage and its ripple component can be approximated as

$$
v_{d c}(t) \approx V_{d c, a v g}+\frac{V_{m} I_{m}}{4 V_{d c, a v g} \omega C} \sin (2 \omega t+\phi)
$$

where $V_{d c, a v g}$ is the average bus voltage.

According to (23), the value of $\sin (2 \omega t+\phi)$, the magnitude of the grid voltage $V_{m}$ and current $I_{m}$ are required to estimate the ripple component of the DC-bus voltage. In the proposed method, the $\alpha$ component of the grid voltage $v_{g-\alpha}$ and the $\beta$ component of the grid current $i_{g-\beta}$ are multiplied to generate the grid double-frequency component. Multiplying $v_{g-\alpha}$ and $i_{g-\beta}$, we have

$$
\begin{aligned}
V_{m} \sin (\omega t) \times I_{m} \cos (w t+\phi) & =\frac{V_{m} I_{m}}{2} \sin (2 \omega t+\phi) \\
& -\frac{V_{m} I_{m}}{2} \sin \phi
\end{aligned}
$$

Thus, the ripple component can be calculated by adding $\left(V_{m} \cdot I_{m} / 2\right) \sin \phi$ in (24) and multiplied by $1 /\left(2 V_{d c, \text { avg }} \omega C\right)$.

\section{B. Sliding mode control}

According to (20), an inherent relationship is presented between the DC-bus voltage and the $d$-axis component of the grid current. In other words, the DC-bus voltage depends on the active power. In this paper, an SMC is designed to calculate the reference active power value.

\section{Sliding surface}

The sliding surface $S$ is chosen as a linear combination of the two state variables, i.e.

$$
S=\alpha_{1} x_{1}+\alpha_{2} x_{2}
$$

where $\alpha_{1}$ and $\alpha_{2}$ represent the sliding coefficients.

The controlled state variables are defined as the DC-link voltage error, $x_{1}$, and the integral of the voltage error, $x_{2}$, which can be expressed as

$$
\begin{gathered}
x_{1}=V_{d c}-V_{d c, \text { ref }} \\
x_{2}=\int\left(V_{d c}-V_{d c, \text { ref }}\right) d t
\end{gathered}
$$

Thus, the sliding surface can be given as

$$
\begin{aligned}
S & =\alpha_{1}\left(V_{d c}-V_{d c, r e f}\right)+\alpha_{2} \int\left(V_{d c}-V_{d c, r e f}\right) d t \\
& =\lambda\left(V_{d c}-V_{d c, r e f}\right)+\int\left(V_{d c}-V_{d c, r e f}\right) d t=0
\end{aligned}
$$

where $\lambda=\alpha_{1} / \alpha_{2}$ is a positive constant, which should be tuned in order to achieve optimized results of settling time, steady state error, and overshoot.

The time derivative of (28) is given as

$$
\dot{S}=\lambda \dot{V}_{d c}+\left(V_{d c}-V_{d c, r e f}\right)
$$

\section{Control law}

Rearranging (6), we can express the input power in the DCbus as

$$
P_{d c}(t)=C v_{d c}(t) \frac{v_{d c}(t)}{d t}+\frac{v_{d c}^{2}(t)}{R_{L}}
$$

where $C v_{d c}(t) \frac{v_{d c}(t)}{d t_{2}}$ is the power flowing into the DC-bus capacitor $\mathrm{C}$ and $\frac{v_{d c}^{2}(t)}{R_{L}}$ is the power consumed by the load resistor $R_{L}$.

By ignoring the switching losses, i.e. assuming the converter as lossless, the input active power $P(t)$ at the grid-side of the power converter is equal to the output power $P_{d c}(t)$ in the DC-bus. Thus, the control law is designed as

$$
u=\left\{\begin{array}{l}
P_{\text {inst. }}^{+}(t), \quad S>0 \\
P_{\text {inst. }}^{-}(t), \quad S<0
\end{array}\right.
$$

where $P_{\text {inst. }}^{+}(t)$ and $P_{\text {inst. }}^{-}(t)$ denote the instantaneous input active power when the corresponding control decision will be directed toward the desired equilibrium point.

Therefore, (30) can be rewritten as

$$
\frac{v_{d c}(t)}{d t}=\frac{u}{C V_{d c}}-\frac{V_{d c}}{R_{L} C}+\delta
$$

where $\delta$ is the disturbance in the DC-bus voltage of the converter. The bound of the external disturbance, $\rho_{s}$, is considered as $|\delta| \leq \rho_{s}<1$, where $\rho_{s}$ is a positive constant [16].

Thus, the control output can be obtained by

$u_{s}=\left[\left(\frac{1}{R_{L} C}-\frac{1}{\lambda}\right) V_{d c}+\frac{1}{\lambda} V_{d c, r e f}-\left(\rho_{s}+k\right) \cdot \operatorname{sign}(S)\right] C V_{d c}$

\section{Observer}

While the SMC law is designed according to the system model, the dynamic performance is still affected by the system parameter uncertainties (e.g., external load variation). In order to overcome the limitations of SMC, an ESO is designed and applied in parallel with the SMC to calculate the reference active power and compensate the system uncertainties, such as the external load variation and plant dynamic variation. Thus, the control output of the proposed scheme can be given as

$$
u=u_{s}+\hat{d}
$$

where $u_{s}$ is the SMC controller output obtained by (33), and $\hat{d}$ the observed value by the observer.

From (17), the capacitor voltage dynamic can be written as

$$
\frac{C}{2} \frac{d v_{d c}}{d t}=\frac{1}{v_{d c}}\left(p^{*}-p_{t}\right)
$$

where $p^{*}=\frac{v_{a b d} i_{d}+v_{a b q} i_{q}}{2}, p_{t}=\frac{v_{d c}^{2}}{R_{p}}+\frac{v_{d c}^{2}}{R_{L}}$, and $R_{P}$ is the equivalent resistance connected in parallel with the load resistor, $R_{L}$, which stands for the switching losses of the converter.

Defining a new variable $z_{1}=\frac{v_{d c}^{2}}{4}$, one can rewrite (35) as

$$
C \frac{d z_{1}}{d t}=u-d(t)
$$

where $d(t)=p_{t}=z_{2}, p^{*}=u$, and the disturbance $z_{2}$ is considered as the extended state. 
TABLE I

Possible States of the Converter

\begin{tabular}{cccccccccc}
\hline \hline & $g_{1}$ & $g_{2}$ & $g_{3}$ & $g_{4}$ & $g_{5}$ & $g_{6}$ & $i_{R 1}$ & $i_{R 2}$ & $v_{a b}$ \\
\hline \multirow{3}{*}{$v_{g}>0$} & 0 & 0 & 0 & 0 & 0 & 0 & $i_{g}$ & $i_{g}$ & $+\left(v_{c 1}+v_{c 2}\right)$ \\
& 0 & 0 & 0 & 0 & 1 & 0 & 0 & $i_{g}$ & $+v_{c 2}$ \\
& 0 & 0 & 1 & 0 & 0 & 0 & 0 & 0 & 0 \\
\hline \multirow{3}{*}{$v_{g}<0$} & 0 & 0 & 0 & 0 & 0 & 0 & $i_{g}$ & $i_{g}$ & $-\left(v_{c 1}+v_{c 2}\right)$ \\
& 0 & 0 & 0 & 0 & 0 & 1 & $i_{g}$ & 0 & $-v_{c 1}$ \\
& 0 & 0 & 0 & 1 & 0 & 0 & 0 & 0 & 0 \\
\hline \hline
\end{tabular}

The derivative of $z_{2}$ is defined as $h$, and can be expressed as

$$
\frac{d z_{2}}{d t}=h(t)
$$

The ESO can be designed as

$$
\begin{gathered}
C \dot{\hat{z}}_{1}=u-\hat{z}_{2}+\beta_{1}\left(z_{1}-\hat{z}_{1}\right)=u-\hat{z}_{2}+\beta_{1} e \\
\dot{\hat{z}}_{2}=-\beta_{2}\left(z_{1}-\hat{z}_{1}\right)=-\beta_{2} e
\end{gathered}
$$

where $e=z_{1}-\hat{z}_{1}, \beta_{1}$ and $\beta_{2}$ are the positive gain parameters of the ESO, $\hat{z}_{1}$ and $\hat{z}_{2}$ the estimated parameters of $z_{1}$ and $z_{2}$, respectively.

The error dynamics are given by

$$
\begin{gathered}
C \dot{e}=-\beta_{1} e-e_{d} \\
\dot{e}_{d}=h(t)+\beta_{2} e
\end{gathered}
$$

where $h(t)=\hat{d}$ is defined as the load power change rate, and $e_{d}=d-\hat{d}$.

The systems expressed in (40) and (41) can be rewritten as

$$
\left[\begin{array}{c}
\dot{e} \\
\dot{e_{d}}
\end{array}\right]=\left[\begin{array}{cc}
-\frac{\beta_{1}}{C} & -\frac{1}{C} \\
\beta_{2} & 0
\end{array}\right]\left[\begin{array}{c}
e \\
e_{d}
\end{array}\right]+\left[\begin{array}{l}
0 \\
1
\end{array}\right] h(t)
$$

To make the error dynamics converge to the equilibrium point, the value of the gain parameters, $\beta_{1}$ and $\beta_{2}$, are required to be chosen so that the polynomial of (42), i.e. $\lambda^{2}+\frac{\beta_{1}}{C} \lambda+\frac{\beta_{2}}{C}$ is Hurwitz stable. Finally, the estimated disturbance to the converter, $\hat{d}$, is added to the control output obtained from the SMC controller to deduce the reference active power value.

\section{FCS-MPC}

In order to predict the grid current and the DC-bus capacitor voltages, (12)-(14) are converted into the form of discrete time by applying the Euler's discretization technique as

$$
\begin{gathered}
i_{g}[k+1]=\left(1-\frac{r T_{s}}{L}\right) i_{g}[k]+\left(v_{g}[k]-v_{a b}[k]\right) \frac{T_{s}}{L} \\
v_{c_{1}}[k+1]=v_{c_{1}}[k]+\frac{T_{s}}{C_{1}} i_{R_{1}}[k]-\frac{T_{s}}{C_{1}} i_{d c}[k] \\
v_{c_{2}}[k+1]=v_{c_{2}}[k]+\frac{T_{s}}{C_{2}} i_{R_{2}}[k]-\frac{T_{s}}{C_{2}} i_{d c}[k]
\end{gathered}
$$

The output voltage of the converter, $v_{a b}$, is obtained from Table I for different switching states. The internal currents of the converter, $i_{R_{1}}$ and $i_{R_{2}}$, can be obtained from the grid current measurement, $i_{g}$, for individual switching states, as shown in Table I. As a result, the unnecessary current measurement can be avoided, which can reduce the cost and complexity of the system. In the proposed system, the current reference of the converter is calculated by

$$
i_{g}=\frac{2 p^{*}}{v_{g d}} \sin (\omega t)-\frac{2 q^{*}}{v_{g d}} \cos (\omega t)
$$

where the value of $\omega t$ is calculated from the PLL, $v_{g d}$ the $d$-axis component of the grid voltage, $p$ the control output obtained from the SMC-ESO controller, and $q$ the reference reactive power value.

In the FCS-MPC method, to realize the desired grid current and balanced voltages across the DC-bus capacitors, the cost function is formulated as

$g=\left(i_{g}^{*}[k+1]-i_{g}[k+1]\right)^{2}+\frac{p^{*}}{v_{r e f .}^{2}}\left(v_{c_{1}}[k+1]-v_{c_{2}}[k+1]\right)^{2}$

where $v_{r e f}$ is the reference value of the desired DC-bus voltage.

\section{E. Stability analysis}

Rearranging (35), we have

$$
\frac{d z_{1}}{d t}=\frac{p^{*}}{C}-\frac{p_{\text {ext. }}}{C}-\frac{4 z_{1}}{C R_{p}}
$$

where $p_{\text {ext. }}$ is the external disturbance.

Applying Laplace transformation, (48) can be written as

$$
z_{1}(s)=\frac{R_{p}}{\left(C s R_{p}+4\right)} p^{*}(s)-\frac{R_{p}}{\left(C s R_{p}+4\right)} p_{\text {ext. }}(s)
$$

By using Laplace domain of (38) and (39), and from Fig. 6, the expression for $G_{d-u}$ can be given as

$$
G_{d-u}(s)=\frac{d(s)}{u(s)}=\frac{\beta_{2}}{C s^{2}+\beta_{1} s+\beta_{2}}
$$

Similarly, the expression for $G_{d-z_{1}}$ can be given as

$$
G_{d-z_{1}}(s)=\frac{d(s)}{z_{1}(s)}=\frac{\beta_{1} \beta_{2}}{C s^{2}+\beta_{1} s+\beta_{2}}-\frac{\beta_{2}\left(\beta_{1}+C s\right)}{C s^{2}+\beta_{1} s+\beta_{2}}
$$

Therefore, based on Fig. 6, the expression for $\hat{d}(s)$ can be obtained as

$$
\hat{d}(s)=\frac{\beta_{2} / C}{s^{2}+\frac{\beta_{1}}{C} s+\frac{\beta_{2}}{C}} u(s)-\frac{\beta_{2} s}{s^{2}+\frac{\beta_{1}}{C} s+\frac{\beta_{2}}{C}} z_{1}(s)
$$

The transfer function of the modified model can be derived as

$$
\begin{aligned}
G_{p}(s) & =\frac{R_{p}}{\left(R_{p} c s+4\right)} \\
& \times \frac{1}{\left(1+\left(\frac{\beta_{2} R_{p} c s}{\left(R_{p} c s+4\right)\left(C s^{2}+\beta_{1} s+\beta_{2}\right)}\right)-\left(\frac{\beta_{2}}{\left(C s^{2}+\beta_{1} s+\beta_{2}\right)}\right)\right)}
\end{aligned}
$$

The system stability and performance are affected by the converter parameter variations, particularly by the DC-link capacitance changes. To evaluate the stability of the system, the closed loop poles of the modified model are examined to confirm the robustness for a range of the DC-bus capacitance variations. In the proposed system, the nominal value of the capacitance is $1 \mathrm{mF}$. The root loci of the model $G_{p}$ with a 


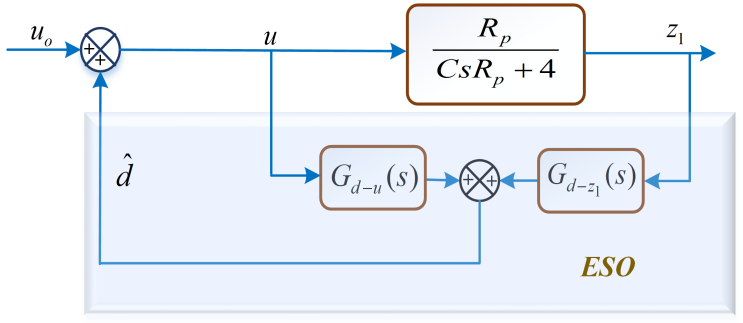

Fig. 6. Equivalent transfer function of ESO.

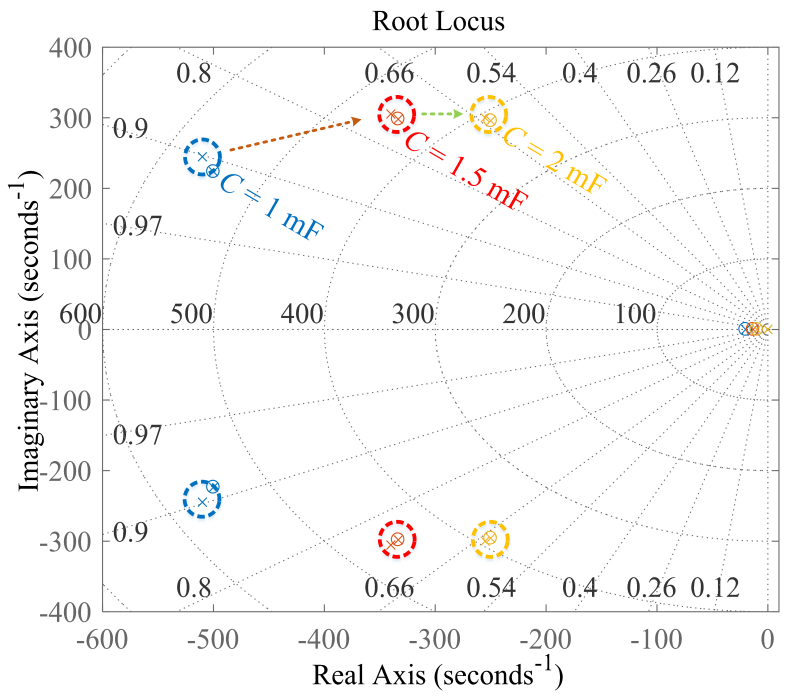

Fig. 7. Root loci of the modified model $\left(G_{p}\right)$ for the variation of DC-bus capacitance.

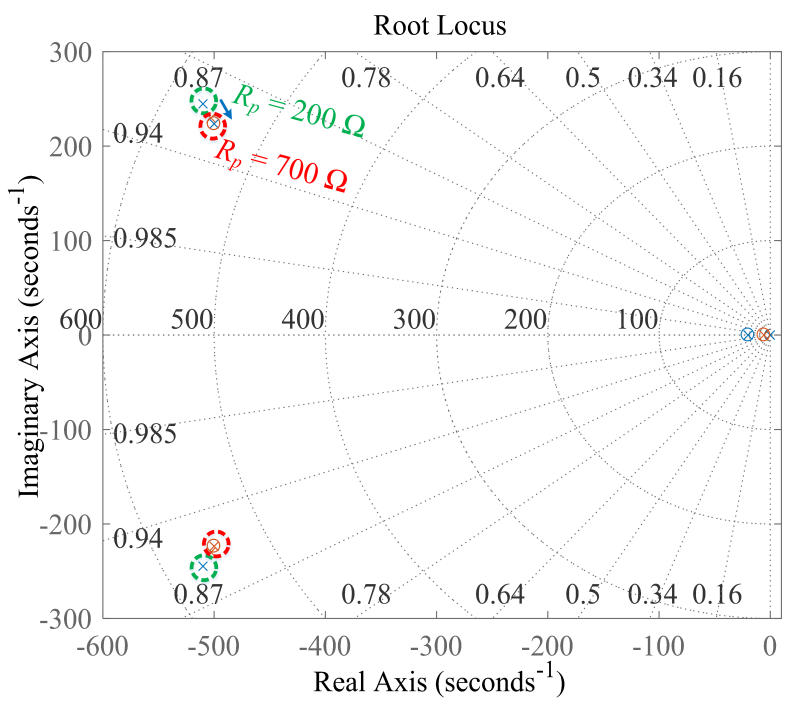

Fig. 8. Root loci of the modified model $\left(G_{p}\right)$ for the variation of $R_{p}$.

large capacitance variation from $1.0 \mathrm{mF}$ to $2 \mathrm{mF}$ is shown in Fig. 7. It can be observed from the root loci that the closed loop pole moves toward the imaginary axis due to the increase of the DC-bus capacitance value, and thus the system becomes comparatively more oscillatory with reduced damping. However, the closed loop poles are far away from the imaginary axis even when the capacitance value reaches $2 \mathrm{mF}$, and the system still shows robustness against this variation.
TABLE II

SYSTEM AND CONTROLLER PARAMETERS

\begin{tabular}{ll}
\hline \hline Paremeter & Value \\
\hline Sampling frequency & $50 \mathrm{kHz}$ \\
Switching frequency (Max.) & $25 \mathrm{kHz}$ \\
Line frequency & $50 \mathrm{~Hz}$ \\
AC input voltage $\left(V_{m}\right)$ & $325 \mathrm{~V}$ \\
DC-bus voltage $\left(v_{d c}\right)$ & $350 \mathrm{~V}$ \\
DC-bus capacitor $\left(C_{1}=C_{2}\right)$ & $2 \mathrm{mF}$ \\
Grid side inductor & $5 \mathrm{mH}$ \\
$R_{p}$ (Nominal) & $700 \Omega$ \\
PI parameters & $k_{p}=0.08, k_{i}=0.2$ \\
ESO parameters & $\beta_{1}=1, \beta_{2}=300$ \\
SMC parameters & $k=20, \rho=0.5, \lambda=0.005$ \\
\hline \hline
\end{tabular}

The root loci of the modified model $G_{p}$ with a variation of $R_{p}$ from $700 \Omega$ to $200 \Omega$ is shown in Fig. 8. As shown, the closed loop poles are far away from the imaginary axis for this variation, and shows robustness for this changes as well.

\section{Performance Evaluation}

To verify the proposed control scheme, the adopted converter with the specifications listed in Table II is tested. The sampling frequency is set to $50 \mathrm{kHz}$. The observed maximum switching frequency with the employed FCS-MPC based inner current tracking controller is $25 \mathrm{kHz}$. To demonstrate the feasibility of the proposed control approach, several test scenarios are implemented and compared with the existing approaches. The inner current control loop remains the same for fair comparison. Fig. 9(a) shows the AC component of the DC-bus ripple voltage, the estimated ripple voltage with the proposed method, and the calculated DC-value of the bus voltage. It can be observed that the proposed method can accurately estimate the DC-bus ripple voltage component. To evaluate the transient performance of the proposed ripple estimation method, a test scenario consists of a step change in the desired DC-bus voltage from $400 \mathrm{~V}$ to $350 \mathrm{~V}$. In this test case, the outer voltage and the inner current control loops remain the same, and a $150 \Omega$ load resistance is connected to the DC-bus. Figs. 9(b) and (c) show the measurement results associated with the traditional notch filter $(\mathrm{NF})$ and the proposed DC-bus ripple estimation methods, respectively, in realizing the reference voltages during this step variation. The traditional NF-based method presents offset error during the transient to estimate the DC-bus ripple voltage. As a result, it degrades the dynamic performance during transients, and shows overshoot, as shown in Fig. 9(b). As shown, the settling time with the traditional NF based method is $\sim 150 \mathrm{~ms}$ and the observed DC-bus voltage overshoot $\sim 5$ V. Fig. 9(c) shows the measurement results associated with the proposed filterless ripple voltage estimation method during the transient. As shown, the settling time with the proposed method is $\sim 50$ ms, which is significantly shorter than that with the NF-based method, and no overshoot is observed.

The second test scenario is designed to compare the external disturbances rejection capability of different DC-bus voltage 


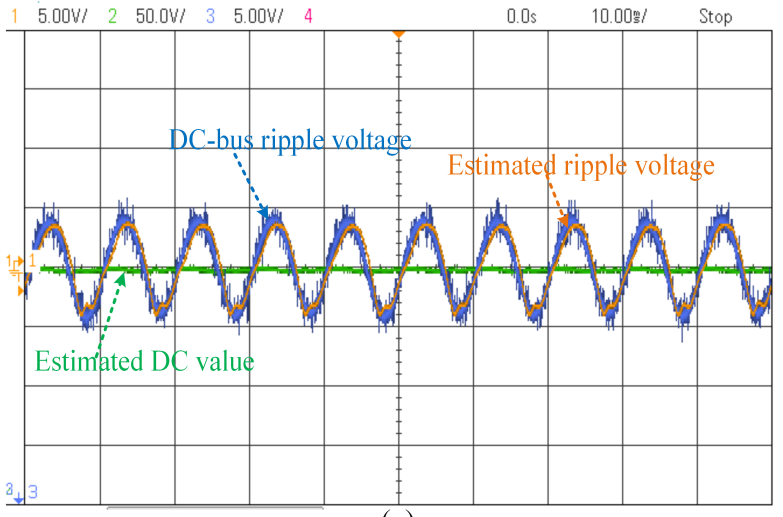

(a)

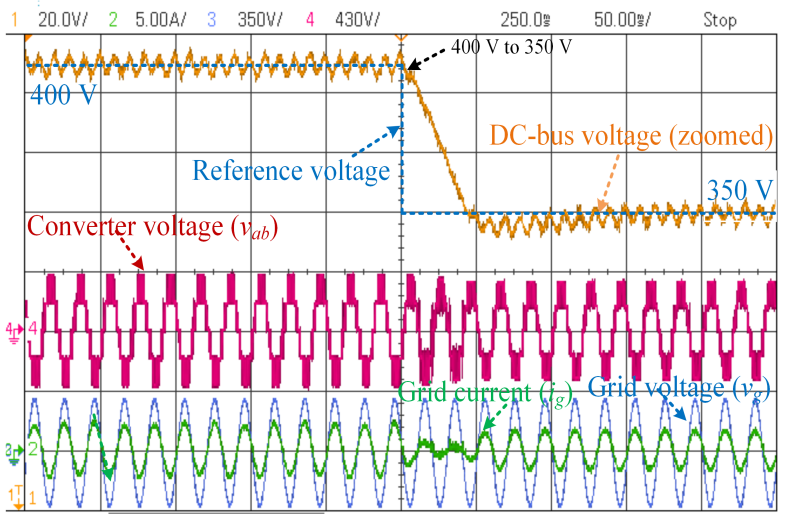

(b)

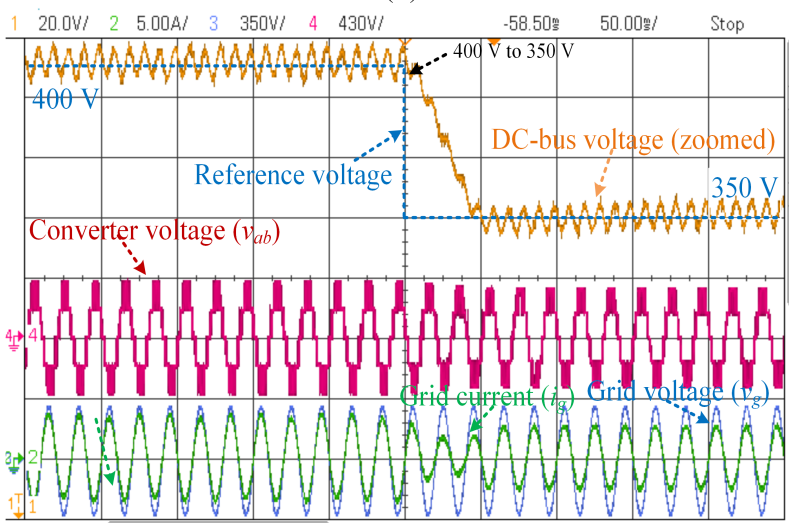

(c)

Fig. 9. Performance comparison of the ripple estimation methods, (a) DC-bus voltage ripple tracking performance of the proposed method, (b) reference DC-bus voltage tracking performance of the conventional NF based method, (c) reference DC-bus voltage tracking performance of the proposed ripple estimation method.

controllers. A step variation in the active power drawn by the converter is considered as the external disturbance, which is realized by the step changes of the DC-bus load. In this case, the proposed ripple estimation method is used to estimate the DC component of the DC-bus voltage. Figs. 10(a)-(d) show the measurement results obtained with the traditional PI controller, the PI combined with the ESO, SMC, and the proposed SMC-ESO approaches, respectively, for the step-up load variations from $200 \Omega$ to $150 \Omega$. The test results show clearly that the PI-based requires $140 \mathrm{~ms}$ to reach the steadystate, and the observed steady-state error is $\sim 7 \mathrm{~V}$. Moreover, the observed maximum voltage fluctuation is $\sim 13 \mathrm{~V}$ for this step load change. In contrast, the PI incorporated with the

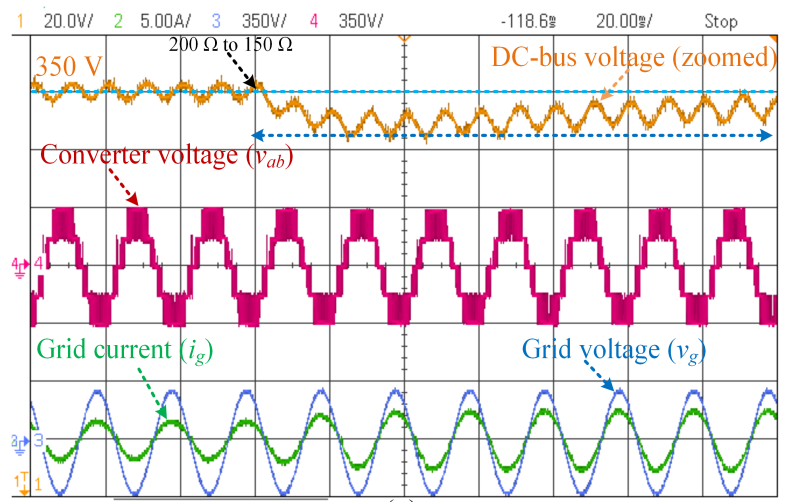

(a)

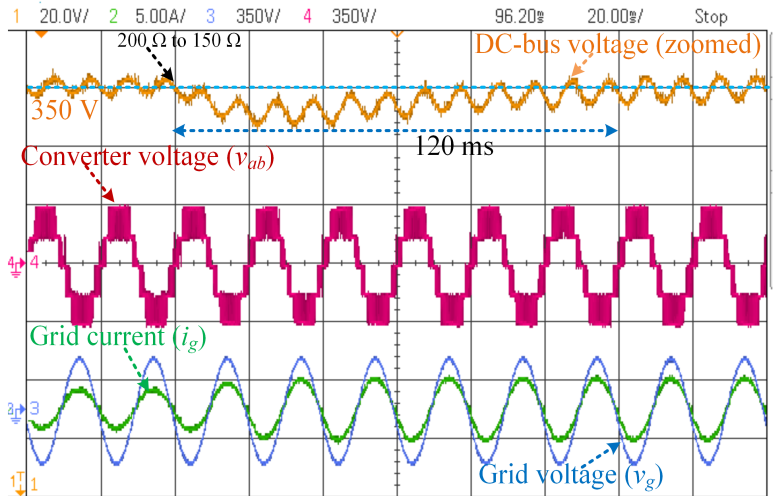

(b)

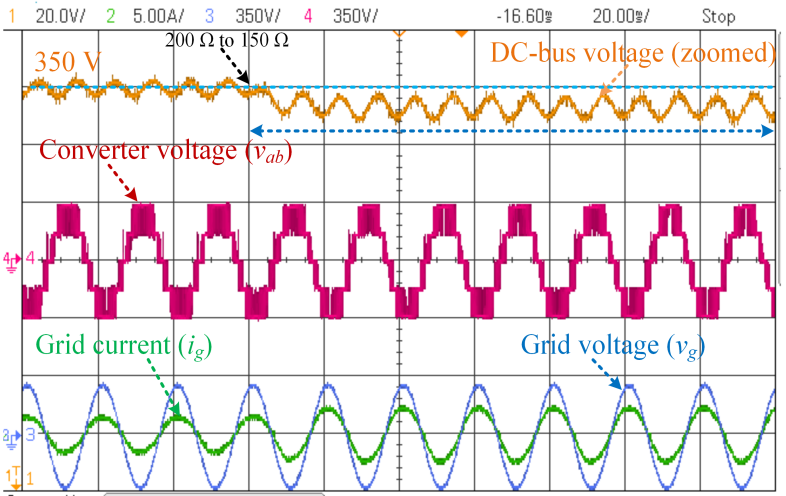

(c)

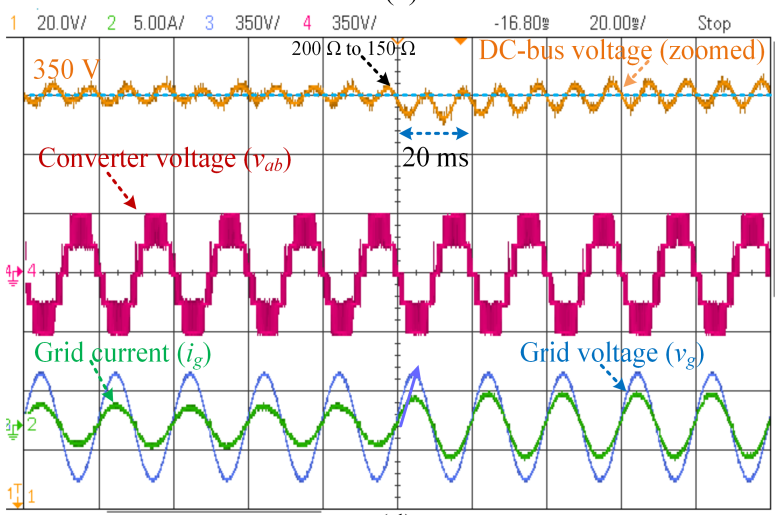

(d)

Fig. 10. Performance comparison of the control methods under step-up load condition, (a) PI, (b) PI-ESO, (c) SMC, (d) SMC-ESO.

ESO presents an improved transient performance during the step-up load change. This method requires $\sim 120$ ms to reach the steady-state and presents zero steady-state error for this 


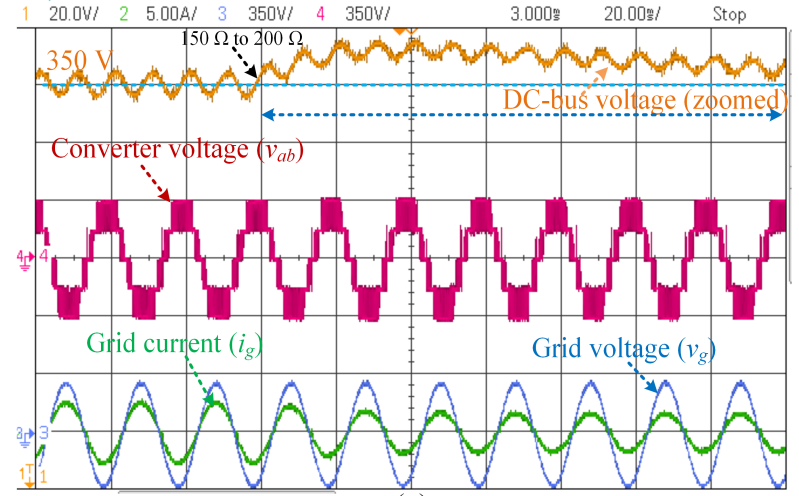

(a)

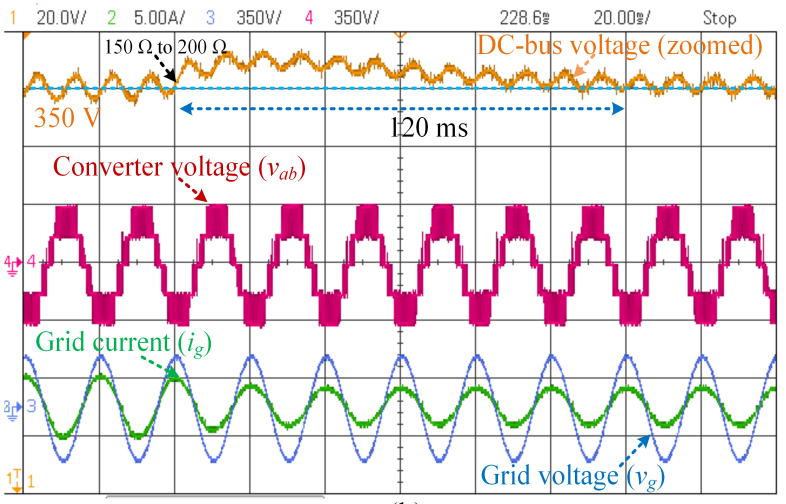

(b)

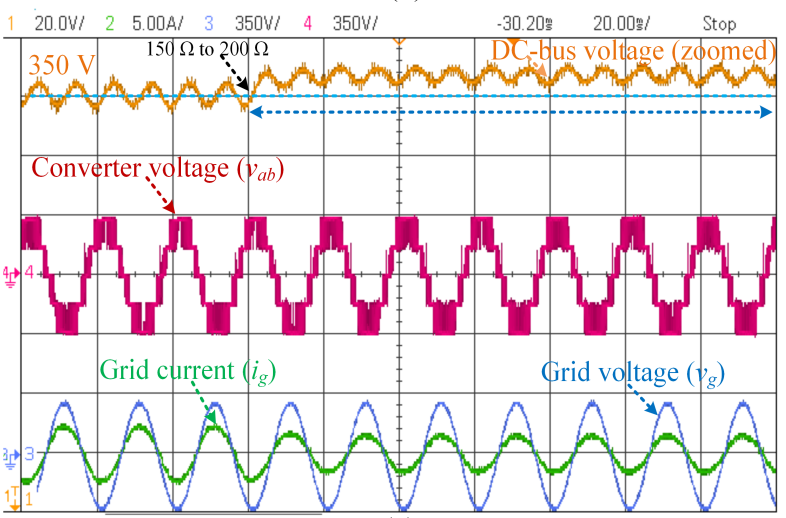

(c)

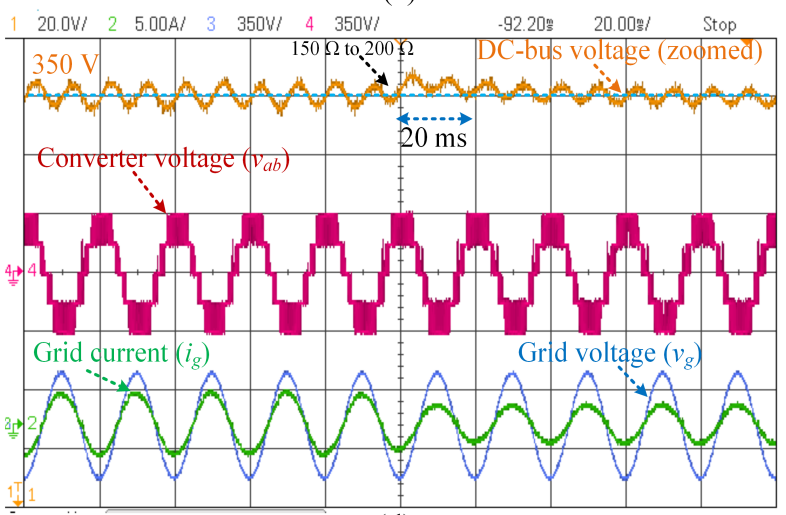

(d)

Fig. 11. Performance comparison of the control methods under stepdown load condition, (a) PI, (b) PI-ESO, (c) SMC, (d) SMC-ESO.

step variation. Fig. 10(c) shows the results obtained by the traditional SMC method. The result shows that a steady-state error is observed for this uncertain load variation with the

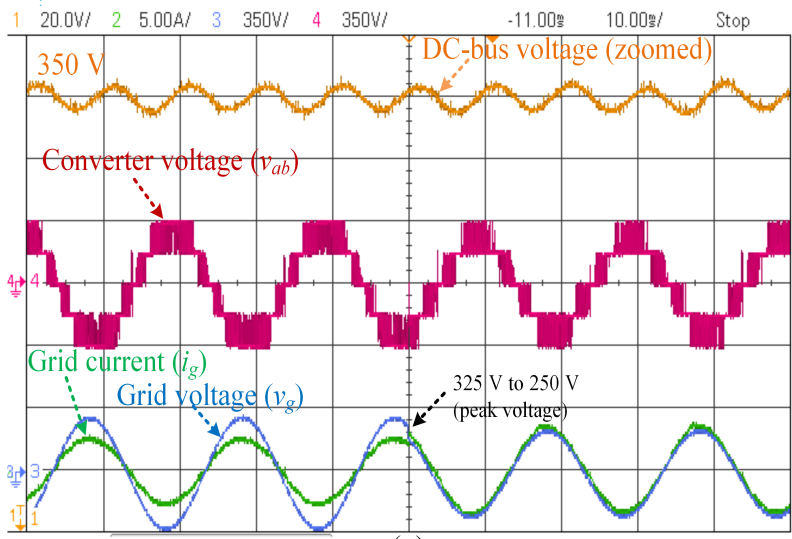

(a)

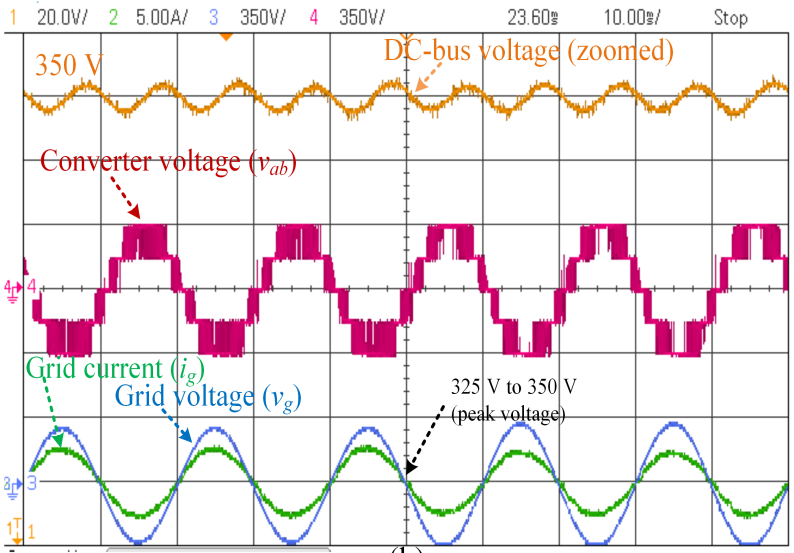

(b)

Fig. 12. Performance of the proposed method under grid voltage variations, (a) amplitude step changes from $325 \mathrm{~V}$ to $250 \mathrm{~V}$, (b) amplitude step changes from $325 \mathrm{~V}$ to $350 \mathrm{~V}$.

SMC method. Fig. 10(d) shows the results obtained with the proposed SMC-ESO method. As shown, the proposed method presents the best performance during the load uncertainties. This method requires $\sim 20 \mathrm{~ms}$ to reach the steady-state and the observed voltage fluctuation is $\sim 3 \mathrm{~V}$ in the transient. Similar set of tests were conducted for step-down load variations from $150 \Omega$ to $200 \Omega$. The measured waveforms are presented in Fig. 11. It can be observed that the conventional PI controller requires $140 \mathrm{~ms}$ to reach the steady-state, and presents a voltage overshoot of $\sim 14 \mathrm{~V}$ and apparent steady-state error. Comparably, the PI-ESO requires $\sim 120 \mathrm{~ms}$ to reach the steady-state and presents an improved transient performance with a voltage overshoot of $\sim 9 \mathrm{~V}$ during the step-load change. Fig. 11(c) shows the results obtained by the traditional SMC method during this step-down load variation, and an apparent steady-state error of $8 \mathrm{~V}$ is observed during this variation. In contrast, the proposed SMC-ESO method presents the best performance during the load step-down. It takes $\sim 20 \mathrm{~ms}$ to reach the steady state with no visible overshoot. Form the results, it is shown clearly that the SMC-ESO presents the best performance in rejecting the uncertain external disturbances to the converter. In addition, the proposed SMC-ESO method also shows improved grid current quality compared to the traditional PI-based method. The observed grid current THD with the proposed method is $4.0 \%$, whereas the conventional PI shows $4.7 \%$ THD in the generated grid current. Moreover, 
the proposed controller performances are also evaluated for the grid disturbance conditions. In the test scenarios, the converter DC-bus reference voltage is set to $350 \mathrm{~V}$. The normal condition is suddenly changed by varying the peak value of the grid voltage from $325 \mathrm{~V}$ to $250 \mathrm{~V}$, and from $325 \mathrm{~V}$ to $350 \mathrm{~V}$. The measurement results are given in Fig. 12. As shown, the generated grid current shows an increment or decrement to compensate those variations on the grid voltage while maintaining the desired DC-bus voltage.

\section{CONCLUSION}

In single-phase AC-DC converters, the main challenge associated with the designing of DC-bus voltage controller is a trade-off between the generated grid current quality and the DC-bus voltage dynamic performance. This tradeoff becomes more difficult when the DC-bus ripple voltage is high due to the use of small bus capacitor. This paper provides an expression for the DC-bus ripple component and introduces a filter-less method to remove this component from the measured voltage completely. Consequently, it enables the reduction of the grid current distortion and presents fast dynamic performance in regulating the DC-bus voltage during the transient. To improve the dynamic performance during the external disturbances, a robust control approach based on the SMC incorporated with an ESO is proposed as the DC-bus voltage controller. The SMC-ESO control approach presents a superior dynamic performance under external disturbances compared to the traditional controllers. A predictive controller is employed as the inner current controller that ensures the equal voltages across the DC-bus capacitors and generates fivelevel voltages in the grid-side.

\section{REFERENCES}

[1] K. G. Pavlou, M. Vasiladiotis, and S. N. Manias, "Constrained model predictive control strategy for single-phase switch-mode rectifiers," IET Power Electronics, vol. 5, no. 1, pp. 31-40, January 2012.

[2] C. Chang, Y. Lin, Y. Chen, and Y. Chang, "Simplified reactive power control for single-phase grid-connected photovoltaic inverters," IEEE Trans. Ind. Electron., vol. 61, no. 5, pp. 2286-2296, May 2014.

[3] M. Vasiladiotis and A. Rufer, "Dynamic analysis and state feedback voltage control of single-phase active rectifiers with dc-link resonant filters," IEEE Trans. Power Electron., vol. 29, no. 10, pp. 5620-5633, Oct 2014.

[4] H. Zhang, X. Li, B. Ge, and R. S. Balog, "Capacitance, dc voltage utilizaton, and current stress: Comparison of double-line frequency ripple power decoupling for single-phase systems," IEEE Industrial Electronics Magazine, vol. 11, no. 3, pp. 37-49, Sep. 2017.

[5] Y. Levron, S. Canaday, and R. W. Erickson, "Bus voltage control with zero distortion and high bandwidth for single-phase solar inverters," IEEE Trans. Power Electron., vol. 31, no. 1, pp. 258-269, Jan 2016.

[6] R. Balog and P. T. Krein, "Automatic tuning of coupled inductor filters," in 2002 IEEE 33rd Annual IEEE Power Electronics Specialists Conference. Proceedings (Cat. No.02CH37289), vol. 2, June 2002, pp. 591-596 vol.2.

[7] M. Karimi-Ghartemani, S. A. Khajehoddin, P. Jain, and A. Bakhshai, "A systematic approach to dc-bus control design in single-phase gridconnected renewable converters," IEEE Trans. Power Electron., vol. 28, no. 7, pp. 3158-3166, July 2013.

[8] S. A. Khajehoddin, M. Karimi-Ghartemani, P. K. Jain, and A. Bakhshai, "Dc-bus design and control for a single-phase grid-connected renewable converter with a small energy storage component," IEEE Trans. Power Electron., vol. 28, no. 7, pp. 3245-3254, July 2013.

[9] R. Wang, F. Wang, D. Boroyevich, R. Burgos, R. Lai, P. Ning, and K. Rajashekara, "A high power density single-phase pwm rectifier with active ripple energy storage," IEEE Trans. Power Electron., vol. 26, no. 5, pp. 1430-1443, May 2011.
[10] H. Li, K. Zhang, H. Zhao, S. Fan, and J. Xiong, "Active power decoupling for high-power single-phase pwm rectifiers," IEEE Trans. Power Electron., vol. 28, no. 3, pp. 1308-1319, March 2013.

[11] S. Harb and R. S. Balog, "Single-phase pwm rectifier with power decoupling ripple-port for double-line-frequency ripple cancellation," in 2013 Twenty-Eighth Annual IEEE Applied Power Electronics Conference and Exposition (APEC), March 2013, pp. 1025-1029.

[12] W. Chen and S. Y. R. Hui, "Elimination of an electrolytic capacitor in ac/dc light-emitting diode (led) driver with high input power factor and constant output current," IEEE Trans. Power Electron., vol. 27, no. 3, pp. 1598-1607, March 2012.

[13] P. T. Krein, R. S. Balog, and M. Mirjafari, "Minimum energy and capacitance requirements for single-phase inverters and rectifiers using a ripple port," IEEE Trans. Power Electron., vol. 27, no. 11, pp. 46904698, Nov 2012.

[14] Y. Hu, Z. Q. Zhu, and M. Odavic, "Instantaneous power control for suppressing the second-harmonic dc-bus voltage under generic unbalanced operating conditions," IEEE Trans. Power Electron., vol. 32, no. 5, pp. 3998-4006, May 2017.

[15] Y. Hu, Z. Zhu, and M. Odavic, "Instantaneous power control for suppressing the second-harmonic dc-bus voltage under generic unbalanced operating conditions," IEEE Trans. Power Electron., vol. 32, no. 5, pp. 3998-4006, May 2017.

[16] T. He, D. D. Lu, L. Li, J. Zhang, L. Zheng, and J. Zhu, "Modelpredictive sliding-mode control for three-phase ac/dc converters," IEEE Trans. Power Electron., vol. 33, no. 10, pp. 8982-8993, Oct 2018.

[17] J. Alcala, E. Barcenas, and V. Cardenas, "Practical methods for tuning pi controllers in the dc-link voltage loop in back-to-back power converters," in 12th IEEE International Power Electronics Congress, Aug 2010, pp. $46-52$.

[18] Z. Zhou, P. J. Unsworth, P. M. Holland, and P. Igic, "Design and analysis of a feedforward control scheme for a three-phase voltage source pulse width modulation rectifier using sensorless load current signal," IET Power Electronics, vol. 2, no. 4, pp. 421-430, July 2009.

[19] R. L. d. A. Ribeiro, T. d. O. A. Rocha, R. M. de Sousa, E. C. dos Santos, and A. M. N. Lima, "A robust dc-link voltage control strategy to enhance the performance of shunt active power filters without harmonic detection schemes," IEEE Trans. Ind. Electron., vol. 62, no. 2, pp. 803-813, Feb 2015.

[20] W. Choi, C. Lam, M. Wong, and Y. Han, "Analysis of dc-link voltage controls in three-phase four-wire hybrid active power filters," IEEE Trans. Power Electron., vol. 28, no. 5, pp. 2180-2191, May 2013.

[21] C. Lam, M. Wong, W. Choi, X. Cui, H. Mei, and J. Liu, "Design and performance of an adaptive low-dc-voltage-controlled lc-hybrid active power filter with a neutral inductor in three-phase four-wire power systems," IEEE Trans. Ind. Electron., vol. 61, no. 6, pp. 2635-2647, June 2014.

[22] S. Eren, M. Pahlevani, A. Bakhshai, and P. Jain, "An adaptive droop dcbus voltage controller for a grid-connected voltage source inverter with lcl filter," IEEE Trans. Power Electron., vol. 30, no. 2, pp. 547-560, Feb 2015.

[23] M. Davari and Y. A. I. Mohamed, "Dynamics and robust control of a grid-connected vsc in multiterminal dc grids considering the instantaneous power of dc- and ac-side filters and dc grid uncertainty," IEEE Trans. Power Electron., vol. 31, no. 3, pp. 1942-1958, March 2016.

[24] A. Yazdani and R. Iravani, Voltage-Sourced Converters in Power Systems: Modeling, Control, and Applications. Wiley-IEEE Press, 2010.

[25] S. A. Khajehoddin, M. Karimi-Ghartemani, A. Bakhshai, and P. Jain, "A power control method with simple structure and fast dynamic response for single-phase grid-connected dg systems," IEEE Trans. Power Electron., vol. 28, no. 1, pp. 221-233, Jan 2013.

[26] A. Bouafia, F. Krim, and J. Gaubert, "Fuzzy-logic-based switching state selection for direct power control of three-phase pwm rectifier," IEEE Trans. Ind. Electron., vol. 56, no. 6, pp. 1984-1992, June 2009.

[27] W. Song, Z. Deng, S. Wang, and X. Feng, "A simple model predictive power control strategy for single-phase pwm converters with modulation function optimization," IEEE Trans. Power Electron., vol. 31, no. 7, pp. 5279-5289, July 2016.

[28] J. Ma, W. Song, S. Wang, and X. Feng, "Model predictive direct power control for single phase three-level rectifier at low switching frequency," IEEE Trans. Power Electron., vol. 33, no. 2, pp. 1050-1062, Feb 2018.

[29] D. Zhou, X. Li, and Y. Tang, "Multiple-vector model-predictive power control of three-phase four-switch rectifiers with capacitor voltage balancing," IEEE Trans. Power Electron., vol. 33, no. 7, pp. 5824-5835, July 2018. 
[30] S. Bosch, J. Staiger, and H. Steinhart, "Predictive current control for an active power filter with lcl-filter," IEEE Trans. Ind. Electron., vol. 65, no. 6, pp. 4943-4952, June 2018

[31] J. Kim, J. Park, and S. Kwak, "Predictive direct power control technique for voltage source converter with high efficiency," IEEE Access, vol. 6, pp. 23540-23 550, 2018.

[32] D. Choi and K. Lee, "Dynamic performance improvement of ac/dc converter using model predictive direct power control with finite control set," IEEE Trans. Ind. Electron., vol. 62, no. 2, pp. 757-767, Feb 2015. 